\title{
Infant and child health status ahead of implementation of an integrated intervention to improve nutrition and survival: a cross-sectional baseline assessment
}

Emmanuel Nene Odjidja* (i), Sonia Hakizimana, Ghislaine Gatasi, Jean-Berchmans Masabo, Gildas Irakoze, Heritier Muzungu, Honorine Murorunkwere, Leila Raissa Ngabirano, Mahmoud Elkasabi and Barbora De Courten

\begin{abstract}
Background: Burundi has one of the poorest child health outcomes in the world. With an acute malnutrition rate of 5\% and a chronic malnutrition rate of 56\%, under five death is 78 per 1000 live births and 47 children for every 1000 children will live until their first birthday. In response to this grim statistics, Village Health Works, a BurundianAmerican organisation has invested in an integrated clinical and community intervention model to improve child health outcomes. The aim of this study is to measure and report on child health indicator ahead of implementing this model.

Methods: A cross sectional design was employed, adopting the Demographic Health Survey methodology. We reached out to a sample of 952 households comprising of 2675 birth, in our study area. Mortality data was analysed with R package for mortality computation and other outcomes using SPSS. Principal component analysis was used to classify households into wealth quintiles. Logistic regression was used to assess strength of associations and significance of association was considered at 95\% confidence level.

Results: The incidence of low birth weight (LBW) was $6.4 \%$ at the study area compared to $10 \%$ at the national level with the strongest predictor being malnourished women (OR 1.4 95\%Cl 1.2-7.2 p =0.043). Fever incidence was higher in the study area (50.5\%) in comparison to $39.5 \%$ nationally. Consumption of minimum acceptable diet was showed a significant protection against fever (OR $0.6495 \% \mathrm{Cl} 0.41-0.94 p=0.042)$. Global Acute Malnutrition rate was $7.6 \%$ and this significantly reduced with increasing age of child. Under-five mortality rate was 32.1 per 1000 live births and infant mortality was 25.7 per 1000 in the catchment with most deaths happening within the first 28 days of life (57.3\%).

(Continued on next page)
\end{abstract}

* Correspondence: emmaodjidja@gmail.com

Village Health Works, BP 1604 Bujumbura, Burundi

(c) The Author(s). 2020 Open Access This article is licensed under a Creative Commons Attribution 4.0 International License, which permits use, sharing, adaptation, distribution and reproduction in any medium or format, as long as you give appropriate credit to the original author(s) and the source, provide a link to the Creative Commons licence, and indicate if changes were made. The images or other third party material in this article are included in the article's Creative Commons licence, unless indicated otherwise in a credit line to the material. If material is not included in the article's Creative Commons licence and your intended use is not permitted by statutory regulation or exceeds the permitted use, you will need to obtain permission directly from the copyright holder. To view a copy of this licence, visit http://creativecommons.org/licenses/by/4.0/ The Creative Commons Public Domain Dedication waiver (http://creativecommons.org/publicdomain/zero/1.0/) applies to the data made available in this article, unless otherwise stated in a credit line to the data. 
(Continued from previous page)

Conclusion: Improving child health status is complex, therefore, investing into an integrated intervention for both mother and child could yield best results. Given that most under-five deaths occurred in the neonatal period, implementing integrated clinical and community newborn care interventions are critical.

Keywords: Under-five mortality, Child health, Infant health, Malnutrition, Childhood morbidity, Low birth weight, Implementation research, Formative evaluation

\section{Background}

Every year, the world experiences 5.4 million deaths of children under five, of which $46.3 \%$ occurs during the first month of life and $81.5 \%$ is from preventable causes [1]. Whereas global under-five mortality rate has reduced from 93 per 1000 live births to 39 per 1000 in 2017, which of sub-Saharan Africa stand at 76 per 1000, implying that 1 in 13 children will die before reaching the 5th birthday [2]. According to a recent United Nations report, with the increasing child population in high mortality countries in the sub-Saharan Africa, it is estimated that the region will accommodate $60 \%$ of all childhood mortalities by 2050 [3]. Within the region, the risk of childhood mortality depends on an array of socio-economic and cultural factors which is distinct from country to country. Children in households of the poorest wealth quintile are two times more likely to die compared to those in the richest quintile [4] and children in rural areas are 1.5 times at risk to die than their cohorts in urban areas [5]. The risk of all under-five deaths is 2.6 times more for children whose mothers have little than primary or no education in comparison to those with mothers who have a minimum of secondary education [1].

Complexities of these sociodemographic factors which influence child survival in sub-Saharan Africa are also mirrored by the inequality in nutritious food distribution resulting in differences in the rates of childhood malnutrition across the region [6-8]. International reports and several individual studies have established the link between all forms of childhood malnutrition and risk of child death in sub-Saharan Africa [9-11], directly accounting for $61 \%$ of all deaths [12]. Malnutrition is a combined effect of food access, frequency and quality which is deeply rooted in several socio-economic, cultural and environmental factors of households. Some of the causes of malnutrition are poverty [13], household food insecurity, illiteracy, dwindling farmlands, poor sanitation and climate change along with several other background factors [14]. While most interventions have focused on increasing uptake of important nutrients and childhood supplements, little attention has been given to addressing these underlying issues in an integrated way $[15,16]$. Nutrition specific interventions have been mostly implemented in parallel with little integration with existing programs hence had little impact on effectively tackling malnutrition, its root causes and all child mortality. Integrating nutritional interventions does not only reduce the risk of childhood mortality [6], but also has long-term effect on overall childhood development, adult health and later life productivity, economic wellbeing as well as epigenetic changes on future generations [17]. Furthermore, emerging evidence has suggested that integrating these two components of nutrition programming can result in significant improvements in costeffectiveness, impact, sustainability and efficiency of these programs [17].

With a wasting and stunting rate of 5 and $56 \%$ respectively, Burundi has one of highest malnutrition rates in the world [18]. Findings from the recent Demographic and Health Surveys DHS [18] show that 78 children in every 1000 will not celebrate their 5th birthday and 47 children per 1000 will not go past the 1st year of birth.

To address this issue, Village Health Works (VHW), a Burundian-American organisation has made significant investment in an integrated program that combines dignified clinical care with targeted food security, economic development, education and community health interlaced with gender and community engagement [19]. Ahead of implementing this program, this study aims to measure and report infant and child health status as well as unpack different components of this model which is influenced on findings of this study.

\section{Methods \\ Study area}

This prospectively collected data collection was conducted at the Vyanda and Rumonge provinces located in the south of Burundi (Fig. 1). Predetermined collines (districts) of VHW's study area constituted the program target area. However, to avoid outliers in the results, the capital towns of both provinces were excluded. Therefore, the sampling frame of this study constituted $18 \mathrm{col}$ lines with a total population of 142,953.

Programmatically, at present, VHW is the only organisation working on infant and child health in the area although this coincides with the implementation of the national free healthcare policy for pregnant women and children under-five. 


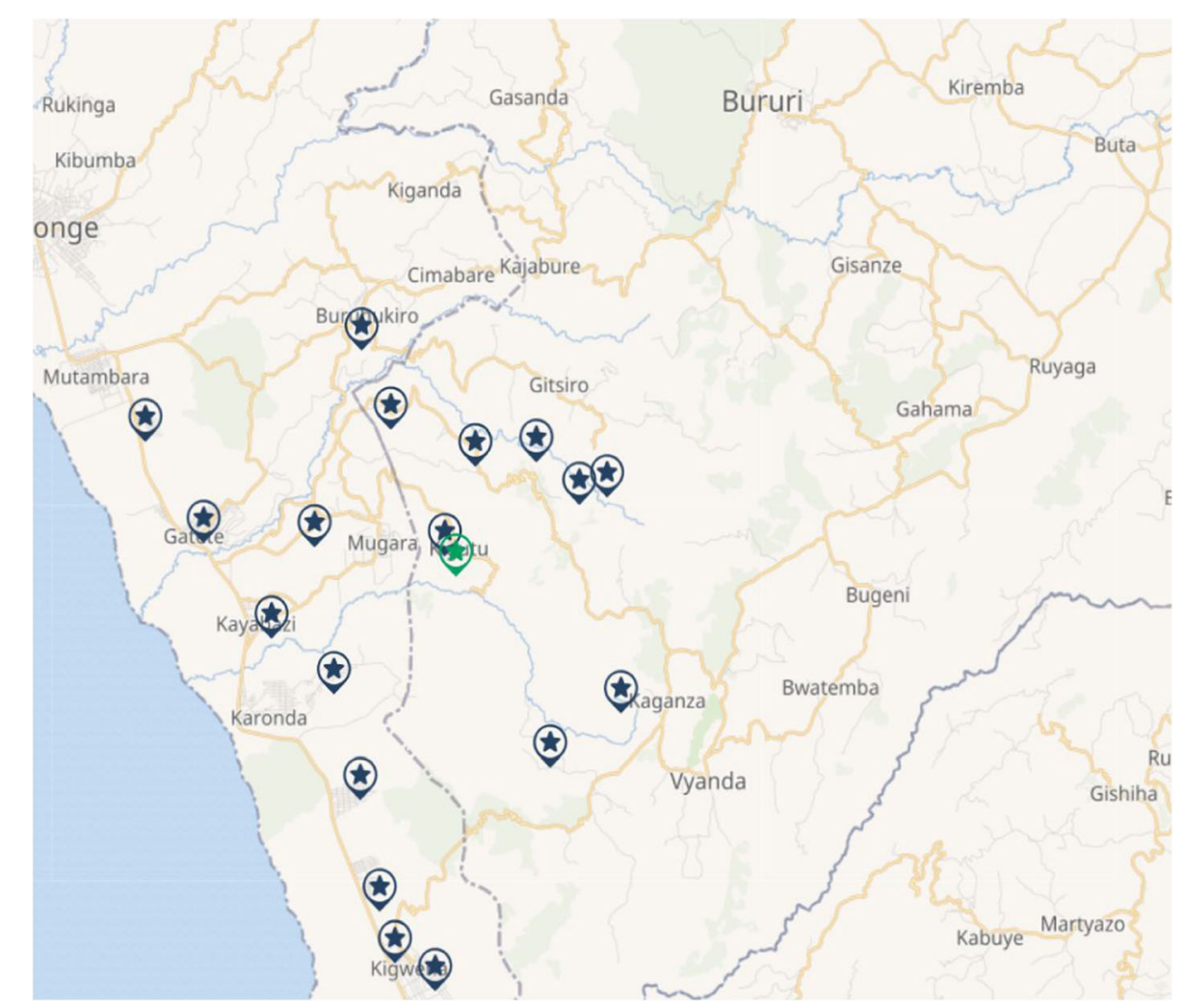

Fig. 1 Map of Study Area constructed using ArcGIS mapping software

\section{Sampling strategy}

A two-stage sampling strategy comprising of cluster and systematic sampling was used for this evaluation. At the first stage, collines along with their respective populations were received from the administrative province authorities. This became the sampling frame from which a probability proportional to size (PPS) was applied to select a desired cluster size of 30 .

The second stage was conducted during field work. Enumerators received households list from the chief of collines (chef de la colline) and depending on the total number of households available in that colline, either a 2nd or 3rd consecutive household was systematically selected after a random 'pen throw' to select the first household. The main sampling units were households and selection was based on the following inclusion and exclusion criteria:

\section{Inclusion criteria}

1. Households with women aged 15 and 49 defined in this evaluation as women of reproductive age with children under-five

2. Children under-five with no life-threatening underlying illnesses and capable to undertake anthropometric measurements.
3. Households with women 15-49 who were residents of the area for at least a year

4. Women of reproductive age who were in sound mind to respond on questions relating to childhood fever and birth histories

\section{Exclusion criteria}

1. Households that did not meet the stated inclusion criteria

2. Households that failed to grant consent via signing or thumb-printing of the form

\section{Sample size calculation}

The determination of an appropriate sample size was based on the methodology of the DHS [18], an international program that conducts national representative surveys on major maternal, infant and child health indicators. Following the statistically robust predetermined conditions of the survey, details of which, have been published elsewhere [18], 952 households were selected. These households then presented 2675 birth histories for computation of infant and child mortality indicators. 


\section{Survey management and data collection}

The entire survey was managed by the operational research, monitoring and evaluation department of VHW. Standard questionnaires were adopted from French version of the standard DHS [20] and United Nations Children's Fund (UNICEF) multiple indicator cluster survey [21]. Questionnaires were segregated into three targeting women (the caregiver in most instances), men and other members of household. Questions about child outcomes were collected from the caregiver and childhood mortality collected through birth histories of women of reproductive age.

Data was collected by seven field teams comprising of a team lead (enumerator), measurer and a supervisor in each team from May 01, 2019 to June 28, 2019. Team leaders interviewed caregivers on child outcomes including taking birth histories and measurers were responsible for taking anthropometric measurements of children and women of reproductive age (height, weight and MidUpper Arm Circumference - MUAC). Supervisors ensured data quality and oversaw random selection of households.

Measurements for resting systolic blood pressure (SBP) and diastolic blood pressure (DBP) were done using a digital portable blood pressure monitor (Panasonic, Germany) which were taken for women of reproductive ages at the households. For each study participant, two measurements were taken, $10 \mathrm{~min}$ apart and the average was taken as the final reading.

\section{Definition of outcomes}

Main outcomes for assessment in this study were: low birth weight, childhood fever and malnutrition and childhood mortality. To allow comparability of our results with national figures, we defined these outcomes according to standard definitions by the DHS [18].

Low birth weight (LBW) was assessed from birth card of the last pregnancy of women within the reproductive age. We classified low birth weight as children who had a weight below $2500 \mathrm{~g}$ at the first measurement after birth.

Fever incidence was defined as child with elevated temperature any level any day within the 2 weeks preceding the survey. This definition is line with the DHS definition and the recall method for data collection has been validated in different settings [22, 23].

Malnutrition was classified under two main measures: acute malnutrition (wasting) and chronic malnutrition (stunting). Global Acute Malnutrition, a combination of moderate and severe wasting was defined as children between 6 and 59 months with weight-for-height (WfH) zscore less than -2 according to the WHO growth standards and global Chronic Malnutrition on the other hand was defined as children with height-for-age z-score less than -2 according to the growth standards. A woman was classified as malnourished if she had MUAC $\leq 23.0 \mathrm{~cm}$ to $\leq 25.5 \mathrm{~cm}$.

From birth and death histories acquired from women and using a synthetic cohort life table approach [24, 25], childhood mortality rates classified as neonatal, postneonatal, infant, child and under-5 mortality were calculated as:

1. Neonatal mortality rate (NNMR): the probability of a child dying between the first day of birth and exact age equal or less than 1 month;

2. Post-neonatal mortality rate (PNMR): the probability of a child dying between ages after 1 month and equal or less than 1 year. This can also be calculated as the difference between IMR and NNMR;

3. Infant mortality rate (IMR): the probability of a child dying between the first day of birth and equal or less than a year after birth;

4. Child mortality rate (CMR): the probability of a child dying between after 1 year of birth and exact age equal or less than 5 years. This is also calculated as the difference between U5MR and IMR;

5. Under-5 mortality rate (U5MR): the probability of a child dying between the first day of birth and exact age equal or less than 5 years.

\section{Definition of exposure variables}

Minimum Acceptable Diet, Blood Pressure status of caregiver, wealth status of households, Nutritional status of caregiver and Household Hunger Scale of households were included as exposure variables for this study.

Minimum Acceptable Diet (MAD) consumed was defined as the proportion of children who consumed four out of seven food types the day preceding the survey. The food types were; grains, root and tubers, legumes and nuts, dairy products (milk, yoghurt, cheese etc.), flesh food (meat, fish, poultry etc.), eggs, Vitamin A-rich fruits and vegetables and other fruits and vegetables. This information was obtain through recall of food consumed $24 \mathrm{~h}$ before the survey.

Blood Pressure (BP) classified was into normal or abnormal (high or low). Normal blood pressure classified as SBP/DBP of $90 / 60 \mathrm{mmHg}$ and $120 / 80 \mathrm{mmHg}$ and abnormal blood pressure, $<90 / 60 \mathrm{mmHg}$ or $\geq 140 / 90$ mmHg.

Household hunger scale, a global indicator for assessing household access and frequency to food was defined as households who reported 'yes' to one or more of the following events: 1 . no food at all in the house; 2 . went to bed hungry, 3. went all day and night without eating. For households that who confirmed ever experiencing any of these events, further questions on frequency were asked which were classified into never (value $=0$ ), rarely 
or sometimes (value $=1$ ), often (value $=2$ ), summing to a total score of 6 . Households with a score between 0 and 1 were classified as 'No hunger detected in households', those with score between 2 and 3, 'Moderate hunger detected in household' and between scores of 4 and 6, 'Severe hunger detected in household'.

In assessing if a child had received Vitamin A supplement, a sample was presented to the caregiver and asked if child had received it 6 months preceding the study. When confirmed, the child was considered as having received Vitamin A supplementation.

Wealth quintiles were constructed from principle component analysis of 15 household items, consisting of household possessions, a state of housing and access to essential services. From the component coefficients generated, rank analysis was applied to classify households into five levels with lowest being the poorest and highest being the richest.

Finally, to determine the influence of malnutrition on some outcomes, it was used as an exposure and the definition is same as stated above in outcomes section.

\section{Data analysis}

Mortality rates were computed using version 0.7 .0 of a predeveloped R package [24] which was originally developed for calculation of childhood mortality using the DHS methodology [25]. Childhood mortality rates were calculated from birth and death histories acquired from women of reproductive age 60 months (5 years) preceding the survey.

All other indicators were calculated using IBM software - SPSS Statistic version 20 [26]. Chi-square test was used to assess relationships between outcomes and exposure variables (those variables disaggregated by the outcome variables). All outcomes were binary, as such a binary logistic regression was used to assess strength of association. However, when independent variables had more than two variables, a multinomial logistic regression was used. Significance of association was considered at $95 \%$ confidence level $p<0.05$ (two-tailed).

Nutrition data was analysed with Emergency Nutrition Assessment (ENA) software [27] for determining the individual malnutrition level of every child (using the WHO defined z-score parameters) and results exported to SPSS for further analysis.

\section{Results}

\section{General characteristics of respondents and households}

Following a response rate of 95.4\%, 2675 live births were recorded for mortality computation from birth histories. Of this, 441 (75.9\% of all households visited) children under-five were identified and eligible for nutrition screening and 581 women of reproductive age were interviewed. Among these women, $74.8 \%$ were married,
$21.3 \%$ single, $1.1 \%$ divorced or separated and $2.0 \%$ widowed. Additionally, $0.8 \%$ children were identified as orphans and $3.3 \%$ reported to have lost either one parent in all households visited. Overall, $74.2 \%$ women were involved in paid employment in farming or within the agricultural value chain. Functional literacy was higher among women $(56.9 \%)$ and $73.8 \%$ of all women reported to have ever attended school.

On general characteristics of households where women and children resided, only $6.7 \%$ of households had access to electricity. Although $85.4 \%$ of households reported to have had access to improved sources of water, $36 \%$ reported to have inconsistencies in supply with longer travelling time for water access (22 min). Fifty percent of households had access to improved sanitation services which among those with unimproved sources, majority (50\%) reported to using pit latrines with slabs. In determining overall socioeconomic status of households, we employed wealth quintiles of households. Combining the two poorest quintiles (Table 1) show that the study area accommodates $43 \%$ compared to only $40 \%$ nationally.

\section{Low birth weight (LBW)}

Overall, the prevalence of low birth weight among eligible women of reproductive age was $31(6.4 \%)$ compared to the $10.5 \%$ at the national level and 5.8 and $6.8 \%$ respectively at Rumonge and Vyanda provinces [18]. Disaggregating the prevalence rate by background information (Table 2), LBW was higher in malnourished women.

All five indicators were used to create a model to predict risk of low birth weight. The model showed that $81 \%$ (Nagelkerke $\mathrm{R}^{2}$ ) of the variance in low birth weight and accurately classified $94.1 \%$ of all cases. Among the five variables, malnutrition among women were significantly associated with low birth weight (OR 1.4 95\% CI 1.2-7.2 $p=0.043$ ) (Table 2).

Table 1 Descriptive characteristics of households in study areas

\begin{tabular}{lll}
\hline Indicator & $\mathrm{n}$ & $\%$ \\
\hline Functional Literacy among women & 331 & 56.9 \\
Percentage of women ever attended school & 429 & 73.8 \\
Households with access to improved water sources & 727 & 85.4 \\
Households with access to improved sanitation sources & 325 & 50.6 \\
Wealth Distribution among Households & & \\
Richest & 94 & 16.2 \\
Fourth & 126 & 21.7 \\
Middle & 112 & 19.2 \\
Second & 118 & 20.3 \\
Poorest & 132 & 22.7 \\
\hline
\end{tabular}


Table 2 Low Birth Weight Incidence disaggregated by background variables

\begin{tabular}{|c|c|c|c|}
\hline Variable Disaggregation & n (\%) & Odds Ratio (OR) & Sig. Level ( $\boldsymbol{P}$-value) \\
\hline LBW Prevalence & $31(6.4 \%)$ & - & - \\
\hline \multicolumn{4}{|l|}{ LBW Prevalence by Province } \\
\hline Rumonge & $21(5.7 \%)$ & Ref & \multirow[t]{2}{*}{0.251} \\
\hline Vyanda & $10(8.7 \%)$ & 0.63 & \\
\hline \multicolumn{4}{|l|}{ LBW Prevalence by BP status of woman } \\
\hline High/Low Blood Pressure & 7(9.1\%) & 1.8 & \multirow[t]{2}{*}{0.195} \\
\hline Normal Blood Pressure & $21(5.3 \%)$ & Ref & \\
\hline \multicolumn{4}{|c|}{ LBW Prevalence by Nutritional Status of woman } \\
\hline Normal Nutritional & $20(4.8 \%)$ & Ref & \multirow[t]{2}{*}{0.043} \\
\hline Malnourished & $8(12.5 \%)$ & 1.40 & \\
\hline \multicolumn{4}{|c|}{ LBW Prevalence by Household Hunger Scale } \\
\hline No hunger detected in household & $17(5.0 \%)$ & 0.32 & 0.300 \\
\hline Moderate Hunger detected in household & $13(9.4 \%)$ & 0.62 & 0.673 \\
\hline Severe Hunger detected in household & $1(14.3 \%)$ & Ref & Ref \\
\hline \multicolumn{4}{|l|}{ LBW Prevalence by Wealth Quintiles } \\
\hline Richest & $2(2.0 \%)$ & 0.30 & 0.142 \\
\hline Fourth & $5(5.2 \%)$ & 0.78 & 0.689 \\
\hline Middle & $9(8.7 \%)$ & 1.37 & 0.56 \\
\hline Second & $6(6.5 \%)$ & Ref & Ref \\
\hline Poorest & $9(9.7 \%)$ & 1.54 & 0.434 \\
\hline
\end{tabular}

Table 3 Prevalence of Fever disaggregated by background variables

\begin{tabular}{|c|c|c|c|}
\hline Variable Disaggregation & n (\%) & Odds Ratio (OR) & Sig. Level (P-value) \\
\hline \multicolumn{4}{|l|}{ Prevalence by Province } \\
\hline Rumonge & $207(48.9 \%)$ & 0.92 & 0.659 \\
\hline Vyanda & $67(51.1 \%)$ & Ref & Ref \\
\hline \multicolumn{4}{|l|}{ Prevalence by Stunting Status of Child } \\
\hline No Stunting & $151(50.0 \%)$ & 1.07 & 0.707 \\
\hline Stunted & $40(48.4 \%)$ & Ref & Ref \\
\hline \multicolumn{4}{|l|}{ Prevalence by Household Hunger Scale } \\
\hline No hunger detected in household & $180(47.5 \%)$ & 0.20 & 0.043 \\
\hline Moderate Hunger detected in household & $85(51.8 \%)$ & 0.23 & 0.050 \\
\hline Severe Hunger detected in household & $9(81.8 \%)$ & Ref & Ref \\
\hline \multicolumn{4}{|c|}{ Prevalence by Minimum Acceptable Diet Consumed } \\
\hline Minimum Acceptable diet consumed & $72(43.6 \%)$ & 0.64 & 0.042 \\
\hline No Acceptable Minimum Diet Consumed & $90(54.9 \%)$ & Ref & Ref \\
\hline \multicolumn{4}{|c|}{ Prevalence by Ownership and Sleeping in Mosquito Nets } \\
\hline Mosquito Net Present & $62(48.4 \%)$ & Ref & Ref \\
\hline Mosquito Net Absent (Not Present) & $133(55.9 \%)$ & 1.57 & 0.009 \\
\hline
\end{tabular}




\section{Incidence of childhood fever}

General fever prevalence among children under 5 was $49.5 \%$ in comparison to 34.3 and $35.3 \%$, respectively, in Rumonge and Vyanda province with $42 \%$ at the national level [18]. Child nutrition was associated with fever incidence and this was evident from an assessment of all indicators on food frequency, access and quality. Household Hunger Scale, an indicator that measures access and frequency of food shows that children in households with severe hunger were more predisposed to fever than those with moderate and no hunger (Table 3). Consumption of acceptable minimum diet, an indicator that measures food quality and diversity consumed by both breastfed and non-breastfed children showed a significant protection against fever (OR 0.64 95\%CI $0.41-$ $0.94 p=0.042$ ). As expected, children that did not sleep in insecticide treated net the night before the survey were more likely to develop fever (1.57).

\section{Childhood malnutrition (acute and chronic)}

Global Acute Malnutrition (wasting) rate in general was $7.6 \%$ and this compares to $5 \%$ at the national level. Among the background variables disaggregated, month of child was significantly associated with risk of acute malnutrition (OR 1.16 95\%CI $0.68-1.96 p<0.001$ ) with the 6 to 17 being the category with highest prevalence. Children situated with household size between 1 and 5 were significantly less likely to develop acute malnutrition (OR 0.32 95\% CI 0.107-0.979) (Table 4).

The Global Chronic Malnutrition (stunting) rate was $45.8 \%$ (95\%CI $42.5-49.1)$ which compares to $55 \%$ at the national level. Prevalence was higher among boys $48.4 \%$ (95\% CI 43.7-53.1) than girls $43.3 \%$ (95\% CI 38.8-47.9). Lack of Vitamin A administration 6 month before the survey was significantly associated with increased risk of childhood stunting (OR 1.76 95\%CI 1.07-2.90).

Table 4 Prevalence of Global Acute Malnutrition (GAM) by background variables

\begin{tabular}{|c|c|c|c|}
\hline Variable Disaggregation & n (\%) & Odds Ratio (OR) & Sig. Level (P-value) \\
\hline GAM Rate & $44(7.6 \%)$ & & \\
\hline \multicolumn{4}{|l|}{ Prevalence of GAM by Communes } \\
\hline Rumonge & $33(7.60 \%)$ & \multirow{2}{*}{$\begin{array}{l}0.933 \\
\text { Ref }\end{array}$} & 0.894 \\
\hline Vyanda & $12(8.60 \%)$ & & Ref \\
\hline \multicolumn{4}{|l|}{ GAM by Nutritional Status of caregiver } \\
\hline Normal Nutritional & $18(3.7 \%)$ & 0.911 & 0.884 \\
\hline Malnourished & $3(4.0 \%)$ & Ref & Ref \\
\hline \multicolumn{4}{|c|}{ Prevalence of GAM by Household Hunger Scale } \\
\hline No Hunger detected in household & $28(6.90 \%)$ & 0.36 & 0.35 \\
\hline Moderate Hunger detected in household & $17(10.90 \%)$ & 0.44 & 0.46 \\
\hline Severe Hunger detected in household & $9(10.50 \%)$ & Ref & Ref \\
\hline \multicolumn{4}{|l|}{ Prevalence of GAM by Wealth Quintiles } \\
\hline Highest & $6(5.20 \%)$ & 0.40 & 0.195 \\
\hline Fourth & $6(5.10 \%)$ & 0.27 & 0.103 \\
\hline Middle & $13(10.80 \%)$ & 1.07 & 0.897 \\
\hline Second & $10(8.90 \%)$ & Ref & Ref \\
\hline Lowest & $12(10.40 \%)$ & 0.26 & 0.103 \\
\hline \multicolumn{4}{|l|}{ Prevalence of GAM by Household size } \\
\hline 1 to5 & $17(7.10 \%)$ & 0.32 & 0.046 \\
\hline 6 to 10 & $27(8.60 \%)$ & Ref & Ref \\
\hline more than 10 & $2(9.50 \%)$ & 1.79 & 0.457 \\
\hline \multicolumn{4}{|l|}{ Prevalence of GAM by Age in Months } \\
\hline 6 to 17 & $6(12.70 \%)$ & 1.16 & $<0.001$ \\
\hline 18 to 29 & $13(8.50 \%)$ & 0.92 & 0.296 \\
\hline 30 to 41 & $9(6.80 \%)$ & Ref & Ref \\
\hline 42 to 53 & $2(5.10 \%)$ & 0.81 & 0.638 \\
\hline 54 to 59 & $1(4.50 \%)$ & 1.02 & 0.332 \\
\hline
\end{tabular}


Table 5 Prevalence of Global Chronic Malnutrition (GCM) by background variables

\begin{tabular}{|c|c|c|c|}
\hline Variable Disaggregation & n (\%) & Odds Ratio (OR) & Sig. Level (P-value) \\
\hline GCM Rate & $266(45.8 \%)$ & & \\
\hline \multicolumn{4}{|l|}{ GCM by Province } \\
\hline Rumonge & $205(46.7 \%)$ & 1.63 & 0.120 \\
\hline Vyanda & $54(39.1 \%)$ & Ref & Ref \\
\hline \multicolumn{4}{|l|}{ GCM by Nutritional Status of caregiver } \\
\hline Normal Nutritional & $221(44.9 \%)$ & 0.93 & 0.777 \\
\hline Malnourished & $35(46.7 \%)$ & Ref & Ref \\
\hline \multicolumn{4}{|l|}{ GCM by Household Hunger Scale } \\
\hline No hunger detected in household & $163(40.9 \%)$ & 0.58 & 0.368 \\
\hline Moderate Hunger detected in household & 90 (53.9\%) & 0.97 & 0.966 \\
\hline Severe Hunger detected in household & $6(54.5 \%)$ & Ref & Ref \\
\hline \multicolumn{4}{|l|}{ GCM by Wealth Quintiles } \\
\hline Richest & 39 (33.9\%) & 0.710 & 0.212 \\
\hline Fourth & $46(40.0 \%)$ & 0.92 & 0.764 \\
\hline Middle & $62(51.7 \%)$ & 1.48 & 0.140 \\
\hline Second & $47(42.0 \%)$ & Ref & Ref \\
\hline Poorest & $65(56.5 \%)$ & 1.80 & 0.029 \\
\hline \multicolumn{4}{|l|}{ GCM rate by Household Size } \\
\hline 1 to5 people & $107(45.1 \%)$ & 1.03 & 0.876 \\
\hline 6 to 10 people & $141(44.5 \%)$ & Ref & Ref \\
\hline more than 10 people & $11(47.8 \%)$ & 1.14 & 0.755 \\
\hline \multicolumn{4}{|c|}{ GCM rate by Vitamin A supplementation for children U5 } \\
\hline Yes Supplementation & $195(42.8 \%)$ & Ref & Ref \\
\hline No Supplementation & $53(57.0 \%)$ & 1.76 & 0.027 \\
\hline
\end{tabular}

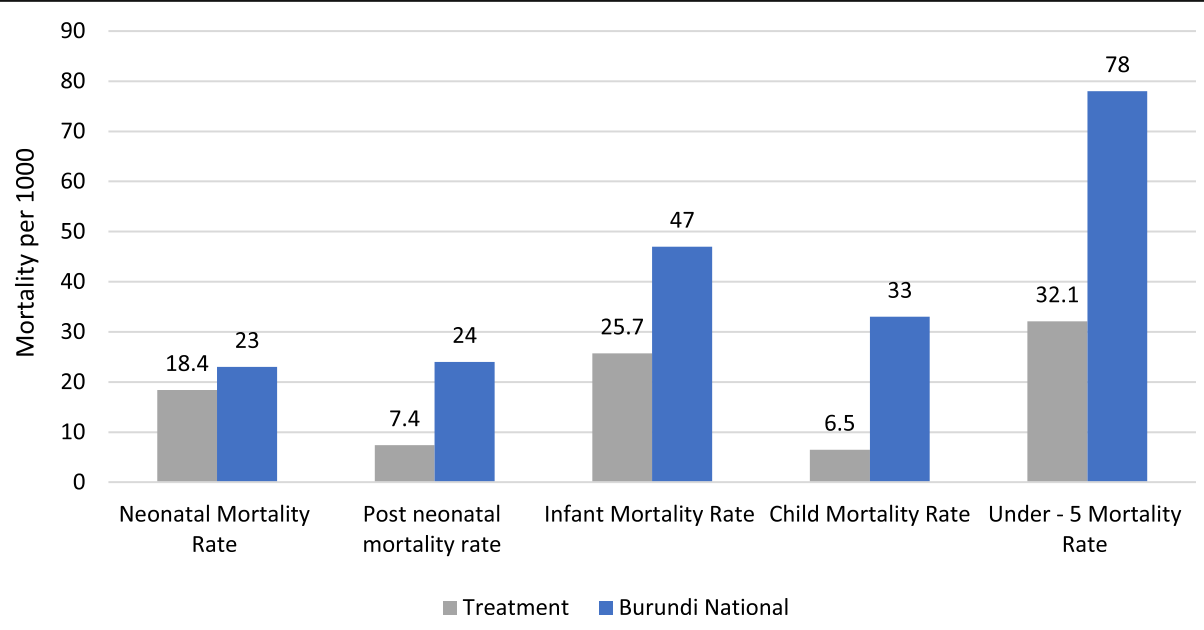

Fig. 2 Comparative childhood mortality - Study area 
Households located in the poorest quintile were 1.8 times more likely to be chronically malnourished (Table $5)$.

\section{Childhood mortality}

In total, 2675 birth histories were collected in the program from which the mortality rates were computed. As illustrated in Fig. 2, neonatal mortality rate was 18.4 per 1000 live births compared to 23 per 1000 nationally. In the study area, neonatal mortality contributes to $57.3 \%$ to all under-5 mortality which compares to $25.7 \%$ nationally.

Post Neonatal Mortality Rate (PNNR) was 7.4 in the study area in comparison to 24 per 1000 nationally, representing $123.3 \%$ more nationally. Infant mortality was $58.6 \%$ higher at the national than in the study area (Fig. 2). Furthermore, child mortality $127.5 \%$ lower than the national figure.

\section{Discussion}

Implementation of child health interventions is complex and therefore implementation approaches should be integrated with other sectors and multilevel of governance. This fundamental philosophy informed our program logic to implement an integrated intervention which priorities will be further determined by areas which showed strongest associations or increased risks with child mortality, stunting and wasting. For example, in our catchment area, most under-5 deaths happened in the first 28 days of life (57.3\%). This particular finding has been reinforced by several studies and global reports. The World Health Organisation estimates that 2.5 million die in the first month of life, amounting to $47 \%$ of all under-five deaths [28]. Akseer et al. [29] further highlight that of these numbers, $73 \%$ die within the first 7 days and $36 \%$ on the first day of birth. Given that half of all these deaths occur within the first $48 \mathrm{~h}$ [29], strengthening all aspects of the health system to provide lifesaving integrated maternal and perinatal intrapartum care is critical. Our integrative intervention to be implemented takes account the incidence of low birth (who are at an increased risk of neonatal death) and will pay special focus to malnourished pregnant women who are even at increased risk. Inclusive in this integrated intervention is a US\$ 20 million capital investment made by VHW for a hospital that will provide advanced diagnosis and treatment for malnourished children including those who suffer from malnutrition related complications.

Malnutrition emerged as one of the challenges to child health in the study area and for acute malnutrition, the risk of acute malnutrition was significantly higher among children aged 6 to 17 months. Earlier studies have confirmed this finding [30, 31] and Amsalu and Tigabu [30] further suggests that children in this age group are 10 times more likely to be acutely malnourished than cohorts in other age brackets. From field observations during the study, we found that especially for young and first-time mothers, there was an apparent difficulty in adhering to exclusive breastfeeding and appropriately introducing complementary foods after the initially six-month window. Both non-adherence to exclusive breastfeeding and inappropriate introduction of complementary foods have been directly linked to increased risk of acute malnutrition and mortality [32, 33]. Among the several community initiatives implemented to reduce incidence of acute malnutrition, our integrative model has a component of working with young and first-time mothers via the 'parenting journey' program. This program will pair up first time mothers with selected experienced and older women who will provide mentorship and support under the supervision of VHW. Evidence also point to increased risk of postpartum maternal depression among first time mothers [34], therefore, we hypothesize that this program will have improvements of maternal mental health as well.

Compared to an average of $33 \%$ in sub-Sahara Africa [35], chronic malnutrition manifested as stunted growth was high in our study area (47.8\%) and was associated with low food diversity and food access. The mean food consumed out of eight food groups assessed was 2.5 with cassava being the most consumed food (87.0\%). In most instances, cassava was consumed along with beans as the single, most important source of protein $(76.6 \%)$. This pattern puts children at risk of inadequate nutrient intake [36] which also is also associated with increased risk of stunted growth. From informal discussions with community members, the preference of cassava emanated from a myriad of problems: lack of farmable land vis-àvis increased household size, resistance of cassava to diseases, inadequate knowledge on diversified food cultivation and preparation. This complex situation will be tackled via creation of food security cooperatives whom will receive agricultural inputs and technical support for a year, after which, they will transition into an independent group. We hypothesize that the formation of cooperatives will mitigate the problem with land access for vulnerable households who are often times at risk of chronic malnutrition.

\section{Study limitations}

Two limitations of the study which should be noted. First, although some variables were statistically associated with the outcomes under study, because of crosssectional design we claim causality at this baseline stage. Another limitation is that apart from malnutrition that children were assessed for, results from all other indicators were acquired via verbal recall of caregivers. This 
could have resulted recall bias and either underestimated or overestimated findings, however, earlier studies have established the validity and reliability of this methodology [22, 23]. Moreover, we initially piloted and contextualised the survey instrument for relevance to the study setting. Also to reduce the possibility of recall bias, samples of supplements and medicines were presented to the caregiver for identification.

\section{Conclusion}

Interventions to improve neonatal, infant and child health are complex and as such, its success will be dependent on the extent to which it is integrated to address underlying the causes. Lessons from VHW's previous program implementation highlights the importance of active community engagement in building trust and solidarity to promote allopathic-based care offered by community health workers and the health facilities. This implies that community members and actors should play key role in every stage of health service planning, program implementation and evaluation.

Equally important in improving under-five health is strengthening all the six components of a health system to provide quality and compassionate care for all. Especially in fragile settings, creating an optimal model of healthcare delivery and building sustainable systems to train the next generation of health workforce is a giant step. This process requires wide stakeholder engagement with government at the centre with a deep focus on sustainability post-intervention.

\section{Abbreviations \\ CMR: Child mortality rate; DHS: Demographic Health Survey; ENA \\ : Emergency Nutrition Assessment; IMR: Infant mortality rate; LBW : Low Birth Weight; MUAC: Mid-Upper Arm Circumference; NNMR: Neonatal mortality rate; OR : Odds Ratio; PNMR: Post-neonatal mortality rate; PPS: Probability Proportional to Size; SMART: Standardized Monitoring and Assessment of Relief and Transitions; SPSS: Statistical Package for the Social Sciences; U5MR: Under-5 mortality rate; UNICEF: United Nations Children's Fund; VHW: Village Health Works; WHO: World Health Organisation}

\section{Acknowledgements}

The authors are grateful to all field assistants and measurers who spent an extended time in the community collecting these data.

\section{Authors' contributions}

ENO, SH, GG, JBM, GI, HM, HM and ME conceptualised the study, ME conceptualised the mortality component and advised on the sampling strategy. ENO, SH, GG, JBM, GI, HM and HM supervised the data collection, cleaned, processed and created indices such as Wealth Distribution using principal component analysis, household hunger scale among others.. ENO, $\mathrm{SH}, \mathrm{GG}, \mathrm{JBM}, \mathrm{Gl}, \mathrm{HM}, \mathrm{HM}, \mathrm{LRN}$ and ME analysed the data. Specifically, ENO, $\mathrm{SH}, J B M, \mathrm{Gl}, \mathrm{HM}$ analysed data on low birth weight and fever, GG analysed data on acute and chronic malnutrition and ME used the R package to calculate the mortality rates. ENO created the logistic model to assess risks. ENO wrote the first draft of the manuscript with inputs and reviews from $\mathrm{ME}, \mathrm{SH}, \mathrm{Gl}, \mathrm{HM}$ and LRN. BdC critically edited the manuscript. All authors read and approved the final manuscript.

\section{Authors' information}

ENO is the Lead for the Operational Research Monitoring and Evaluation Department for Village Health Works and based in Kigutu, Burundi. SH, GG,
JBM, Gl, HM and HM are members of the department and also based in Kigutu, Burundi. ME is the Senior Survey Sampling Statistician at the Demographic Health Survey Program and is largely responsible for sampling for several countries. He also provides technical support on calculation of major indicators such as mortality rates calculation. BdC is a Professor of Medicine and Specialist in Epidemiology and Public Health at the School of Clinical Sciences at Monash Health, University of Monash, Melbourne, Australia, General Physician at Melbourne, Monash Health, Australia.

\section{Funding}

The Survey was funded by the Vitol Foundation.

\section{Availability of data and materials}

The data used for analysis in this manuscript are available from the Research, Monitoring and Evaluation Department of VHW. Data is restricted but available from corresponding author upon reasonable request.

\section{Ethics approval and consent to participate}

The study was approved by the Rumonge and Vyanda local ethics under the National Burundian Ethics Committee which is under the Ministry of Health. The study was also internally commissioned and approved by senior management of VHW after review of the study protocol. Study participants signed a consent form ahead of interview. Parents signed the consent form on behalf of the children who underwent anthropometric assessment for malnutrition screening.

\section{Consent for publication}

Not applicable.

\section{Competing interests}

We declare no competing interests.

Received: 9 August 2020 Accepted: 20 August 2020

Published online: 05 October 2020

\section{References}

1. You D, Hug L, Ejdemyr S, Idele P, Hogan D, Mathers C, Gerland P, New JR, Alkema L. United Nations Inter-agency Group for Child Mortality Estimation (UN IGME) Global, regional, and national levels and trends in under-5 mortality between 1990 and 2015, with scenario-based projections to 2030: a systematic analysis by the UN Inter-agency Group for Child Mortality Estimation. Lancet. 2015;386(10010):2275-86.

2. World Health Organization. Global Health Estimates 2016: Deaths by cause, age, sex, by country and by region, 2000-2016. Geneva: WHO; 2018.

3. United Nations Inter-agency Group for Child Mortality Estimation (UN IGME) Levels \& Trends in Child Mortality: Report 2018, Estimates developed by the United Nations Inter-agency Group for Child Mortality Estimation. New York: United Nations Children's Fund; 2018.

4. Chao F, You D, Pedersen J, Hug L, Alkema L. National and regional under-5 mortality rate by economic status for low-income and middle-income countries: a systematic assessment. Lancet Glob Health. 2018;6(5):e535-47.

5. United Nation's Children Fund. Advantage or Paradox? The Challenge for Children and Young People of Growing Up Urban. New York: Data and Analytics Section, Division of Data, Research and Policy in UNICEF HQ; 2018. p. 5-7. Available at: https://unicef.at/fileadmin/media/Infos_und_Medien/ Info-Material/Lage_der_Kinder_weltweit/AdvantageOrParadox_web_FINAL. pdf Accessed 25 Sep 2019.

6. Schroeder DG, Brown KH. Nutritional status as a predictor of child survival: summarizing the association and quantifying its global impact. Bull World Health Organ. 1994;72(4):569.

7. Caulfield LE, de Onis M, Blössner M, Black RE. Undernutrition as an underlying cause of child deaths associated with diarrhea, pneumonia, malaria, and measles. Am J Clin Nutr. 2004;80(1):193-8.

8. Zere $\mathrm{E}, \mathrm{McIntyre} \mathrm{D}$. Inequities in under-five child malnutrition in South Africa. Int J Equity Health. 2003;2(1):7.

9. Pelletier DL, Frongillo EA. Changes in child survival are strongly associated with changes in malnutrition in developing countries. J Nutr. 2003;133(1): 107-19.

10. Black RE, Victora CG, Walker SP, Bhutta ZA, Christian P, De Onis M, Ezzati M, Grantham-McGregor S, Katz J, Martorell R, Uauy R. Maternal and child 
undernutrition and overweight in low-income and middle-income countries. Lancet. 2013;382(9890):427-51.

11. Jackson AA, Ashworth A, Khanum S. Improving child survival: malnutrition task force and the paediatrician's responsibility. Arch Dis Child. 2006;91(8): 706-10

12. Black RE, Morris SS, Bryce J. Where and why are 10 million children dying every year? Lancet. 2003;361(9376):2226-34.

13. Petrou S, Kupek E. Poverty and childhood undernutrition in developing countries: a multi-national cohort study. Soc Sci Med. 2010;71(7):1366-73.

14. Bain LE, Awah PK, Geraldine N, Kindong NP, Siga Y, Bernard N, Tanjeko AT. Malnutrition in sub-Saharan Africa: burden, causes and prospects. Pan African Medical Journal. 2013;15(1):120.

15. Bhutta ZA, Ahmed T, Black RE, Cousens S, Dewey K, Giugliani E, Haider BA, Kirkwood B, Morris SS, Sachdev HPS, Shekar M. What works? Interventions for maternal and child undernutrition and survival. Lancet. 2008;371(9610): 417-40.

16. Alderman $\mathrm{H}$. Linkages between poverty reduction strategies and child nutrition: an Asian perspective. Econ Political Wkly. 2005;40(46):4837-42. http://siteresources.worldbank.org/NUTRITION/Resources/281846-1131636 806329/NutritionStrategy.pdf.

17. Ruel MT, Alderman H, Maternal and Child Nutrition Study Group. Nutritionsensitive interventions and programmes: how can they help to accelerate progress in improving maternal and child nutrition? Lancet. 2013;382(9891): 536-51.

18. Ministère à la Présidence chargé de la Bonne Gouvernance et du Plan [Burundi] (MPBGP), Ministère de la Santé Publique et de la Lutte contre le Sida [Burundi] (MSPLS), Institut de Statistiques et d'Études Économiques du Burundi (ISTEEBU), et ICF. Troisième Enquête Démographique et de Santé. Bujumbura: ISTEEBU, MSPLS, et ICF; 2017.

19. Village Health Works. Kigutu Hospital \& Women's Health Pavilion — Village Health Works: Village Health Works; 2018. Available at: https://www. villagehealthworks.org/whptext Accessed 11 Oct 2019.

20. Demographic Health Survey, 2020. The DHS Program - DHS Questionnaires. Dhsprogram.com. Available at: <https://dhsprogram.com/What-We-Do/ Survey-Types/DHS-Questionnaires.cfm> Accessed 12 Aug 2020.

21. UNICEF, 2019. Tools and Questionnaires - UNICEF MICS. Mics.unicef.org. Available at: $<$ http://mics.unicef.org/tools?round=mics6> Accessed 12 Aug 2020.

22. Natland ST, Andersen LF, Nilsen TIL, Forsmo S, Jacobsen GW. Maternal recall of breastfeeding duration twenty years after delivery. BMC Med Res Methodol. 2012;12(1):179.

23. Gofin R, Neumark YD, Adler B. Birthweight recall by mothers of Israeli children. Public Health. 2000;114(3):161-3.

24. Elkasabi M. Calculating fertility and childhood mortality rates from survey data using the DHS. Rates R package. PloS one. 2019;14(5):e0216403.

25. Croft TN, Marshall AMJ, Allen CK, et al. Guide to DHS statistics. Rockville: ICF; 2018. [cited 2019 January 29]. Available from: https://www.dhsprogram. com/publications/publication-DHSG1-DHS-Questionnaires-and-Manuals.cfm.

26. Verma, J.P., 2012. Data analysis in management with SPSS software. Springer Science \& Business Media.

27. Assessment EN. Software for standardized monitoring and assessment of relief and transitions (SMART), version October 2007; 2014.

28. World Health Organisation (2019). Newborns: reducing mortality. Who.int. Available at: https://www.who.int/news-room/fact-sheets/detail/newbornsreducing-mortality Accessed 10 Oct 2019.

29. Akseer N, Lawn JE, Keenan W, Konstantopoulos A, Cooper P, Ismail Z Thacker N, Cabral S, Bhutta ZA. Ending preventable newborn deaths in a generation. Int J Gynecol Obstet. 2015;131:S43-8.

30. Amsalu S, Tigabu Z. Risk factors for ever acute malnutrition inchildren under the age of five: a case-control study. Ethiop J Health Dev. 2008;22(1):21-5.

31. Walton E, Allen S. Malnutrition in developing countries. Paediatr Child Health. 2011;21(9):418-24.

32. Odjidja EN, Hakizimana S. Data on acute malnutrition and mortality among under-5 children of pastoralists in a humanitarian setting: a cross-sectional standardized monitoring and Assessment of relief and transitions study. BMC Research Notes. 2019;12(1):434.

33. Egata G, Berhane $Y$, Worku A. Predictors of acute undernutrition among children aged 6 to 36 months in east rural Ethiopia: a community based nested case-control study. BMC Pediatr. 2014;14(1):91.

34. Abbasi S, Chuang CH, Dagher R, Zhu J, Kjerulff K. Unintended pregnancy and postpartum depression among first-time mothers. J Women's Health. 2013;22(5):412-6.
35. Measure D. Demographic and health surveys STATcompiler. Calverton: Macro International Inc; 2019.

36. Stephenson K, Amthor R, Mallowa S, Nungo R, Maziya-Dixon B, Gichuki S, Mbanaso A, Manary M. Consuming cassava as a staple food places children 2-5 years old at risk for inadequate protein intake, an observational study in Kenya and Nigeria. Nutr J. 2010;9(1):9.

\section{Publisher's Note}

Springer Nature remains neutral with regard to jurisdictional claims in published maps and institutional affiliations.
Ready to submit your research? Choose BMC and benefit from:

- fast, convenient online submission

- thorough peer review by experienced researchers in your field

- rapid publication on acceptance

- support for research data, including large and complex data types

- gold Open Access which fosters wider collaboration and increased citations

- maximum visibility for your research: over $100 \mathrm{M}$ website views per year

At BMC, research is always in progress.

Learn more biomedcentral.com/submissions 